\title{
Simulation Modeling of a Check-in and Medication Reconciliation Ambulatory Clinic Kiosk
}

\author{
Blake Lesselroth, MD, MBI ${ }^{1,2, *}$, William Eisenhauer, MEng ${ }^{1}$, Shawn Adams ${ }^{1,2}$, \\ David A. Dorr, MD, MS ${ }^{2}$, Christine Randall ${ }^{1}$, Paulette Channon ${ }^{1}$, \\ Kas Adams, MPH ${ }^{1}$, Victoria Church, RN, CNS ${ }^{1}$, Robert Felder, DDS, MPH ${ }^{1}$, \\ David Douglas, $\mathbf{M D}^{1}$ \\ ${ }^{1}$ Portland, Oregon Veterans Affairs Medical Center, \\ 3710 SW US Veterans Hospital Drive, Portland, Oregon, 97239, USA \\ ${ }^{2}$ Oregon Health and Science University, \\ Department of Medical Informatics and Clinical Epidemiology, \\ 3181 SW Sam Jackson Park Road, Portland, Oregon, 97239, USA
}

Submitted August 2010. Accepted for publication January 2011.

\begin{abstract}
Gaps in information about patient medication adherence may contribute to preventable adverse drug events and patient harm. Hence, health-quality advocacy groups, including the Joint Commission, have called for the implementation of standardized processes to collect and compare patient medication lists. This manuscript describes the implementation of a self-service patient kiosk intended to check in patients for a clinic appointment and collect a medication adherence history, which is then available through the electronic health record. We used business process engineering and simulation modeling to analyze existing workflow, evaluate technology impact on clinic throughput, and predict future infrastructure needs. Our empiric data indicated that a multi-function healthcare kiosk offers a feasible platform to collect medical history data. Furthermore, our simulation model showed a non-linear association between patient arrival rate, kiosk number, and estimated patient wait times. This study provides important data to help administrators and healthcare executives predict infrastructure needs when considering the use of self-service kiosks.
\end{abstract}

Keywords: reengineering, healthcare service, waiting time, user-computer interface, medication error

*Corresponding author: Blake Lesselroth, Mail Code P3MED, Portland, Oregon Veterans Affairs Medical Center, 3710 SW US Veterans Hospital Drive, Portland, Oregon, 97239, USA, Blake.Lesselroth@ va.gov, Tel: (503) 220-8262 extension 55998. 


\section{INTRODUCTION}

\subsection{Background}

The Institute of Medicine reported in "Preventing Medication Errors" that medicationprescribing errors are a major root cause of preventable healthcare injuries [1-3]. These errors are often associated with system-based weaknesses at interfaces-in-care and are caused by discontinuity in providers, information gaps, and changes in patient health status [4-9]. In the ambulatory care setting, accurate medication management is further confounded by variable patient compliance, low healthcare literacy, and a fragmented healthcare infrastructure characterized by multiple pharmaceutical dispensaries [10-15].

Because incomplete transfer of medication information has been highlighted as a major precipitant of healthcare errors, efforts to harmonize pharmacy documentation may improve overall healthcare quality [16, 17]. Medication reconciliation (MR), which consists of reviewing medications, comparing documentation, identifying discrepancies, and updating patient medication lists, has been widely accepted by organizations as a strategy to improve patient safety [18]. Studies have shown that MR processes inserted during clinical encounters can help identify medication discrepancies and potentially reduce unintended prescribing errors [4, 8, 19-23]. Reduction in prescribing errors, in turn, may reduce drug-drug interactions, adverse drug reactions, and iatrogenic injury $[5,20,24,25]$.

Although multiple healthcare-quality advocacy groups have campaigned for the institution of MR processes at every clinical encounter, substantial barriers preclude widespread adoption [26-29]. First, there is surprisingly little data on MR implementations to make a decision about what constitutes best practice [17, 30-33]. For example, it is unclear how to improve history collection when patients may recall only one-third of their medications $[12,34,35]$. Second, most published case reports of standardized implementations require substantial resource allocation (e.g., additional pharmacy staff or "pill clinics") [8, 33, 36-40]. Settings without such resources encumber the primary clinic provider responsible for reconciling medications, which can take upwards of 30 minutes per encounter [37, 41].

Consequently, healthcare facilities need novel technologies and system-based strategies to improve the efficiency and reliability of MR efforts. Our process improvement team hypothesized that a self-service kiosk could support MR without disrupting clinic throughput. To this end, we developed the Automated Patient History Intake Device (APHID), a healthcare clinic kiosk, to complete administrative transactions and gather a medication history. We applied business process engineering and medical informatics strategies to integrate the new data streams into clinic workflow.

During kiosk piloting, the team encountered implementation challenges associated with business integration and built-environment configuration. Little evidence-based literature existed to forecast kiosk use statistics, and skeptics were concerned that the technology would be too difficult for patients to use, thus impeding clinic throughput. Consequently, we applied a combination of business analysis techniques including process mapping, time-and-motion analysis, and simulation modeling to better diagnose system weaknesses, predict resource needs, and optimize performance. 


\subsection{Purpose}

The purpose of this manuscript is to (1) describe how we used a locally-developed, multi-purpose kiosk to support ambulatory clinic MR along with other administrative transactions, (2) show how business process and simulation modeling were used to estimate infrastructure impact, and (3) propose strategies for kiosk deployment in an ambulatory care clinic.

\subsection{Literature Review on Healthcare Kiosks}

Many industries outside of healthcare have used self-service kiosks to extend service offerings, increase throughput, and capture new revenue [42, 43]. Conversely, the healthcare industry has been slow to adopt kiosk technology. Most kiosk systems designed for health enterprise integration (as opposed to stand-alone systems such as informational or educational kiosks) perform relatively simple administrative transactions including check-in, demographic review, or insurance verification [42, 44].

There have been several reports of check-in kiosk technology improving operational efficiency and maximizing clinic throughput [42, 44-46]. However, these reports are largely anecdotal and none includes comparative data [47-49]. Furthermore, a number of development teams have described kiosk prototypes designed to collect complex medical information or provide clinical decision support [50-54]. For example, kiosks have been used to evaluate chronic illness progression, score clinical outcomes, assist with diagnosis, and triage patients [45, 50, 52-55]. However, most of these reports describe single function software applications that do not integrate with legacy technologies or workflow.

There is very little evidence-based literature describing kiosk implementations or outcomes with regards to process efficiency, cost-savings, or clinical care. This represents an important gap in the literature and limits any generalizability in healthcare. Multimodal evaluative studies of kiosk implementations are required to address the business needs of both healthcare executives and front-line providers. Qualitative and quantitative data are needed to help enterprise strategic planning and to inform large-scale healthcare implementations.

\section{METHODS}

\subsection{Description of Usual Care Clinic Processes}

The Portland Oregon Veterans Affairs Medical Center (PVAMC) is a federal 303-bed facility offering a mixture of acute care, primary care, and specialty care services. It serves as the Veterans Affairs' (VA) quaternary referral center for Oregon, Southern Washington, and parts of Idaho. The PVAMC Primary Care division manages 40,000 veterans across nine clinic locations and completes an estimated 84,800 outpatient visits per year. The average Portland primary care patient is 60.8 years old $(20-25 \%>75 y)$ and takes an average of eight medications. In Oregon, an estimated $92-97 \%$ of patients are male and an estimated $65-70 \%$ have at least some college or associate's degree training [56, 57]. Greater than $90 \%$ of patients receive some or all of their medications from the VA.

Providers use the VA's computerized patient record system (CPRS), a fully functional electronic health record (as defined by the Office of the National 


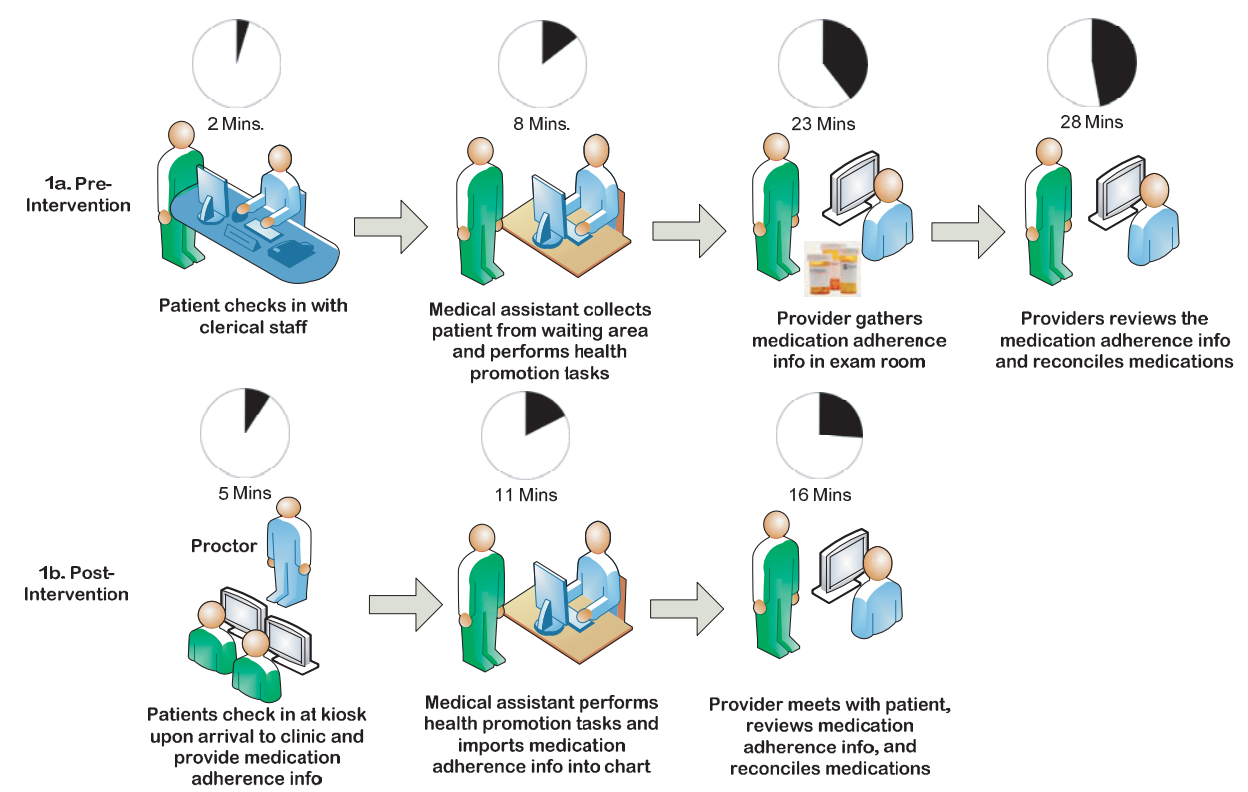

Figure 1. Workflow for the (a) pre-intervention and (b) post-intervention registration processes with cumulative cycle time. Reconciliation times based on published estimates [75].

Coordinator), to enter orders and view medical information stored in the VA database, the Veterans Health Information Systems and Technology Architecture (VistA) [58, 59]. The VA pharmacy system supports the medication supply chain; prescribers enter electronic prescriptions and pharmacists fill and dispense medications from local or regional inventories. Facilities archive all medication transactions in VistA.

Before the APHID pilot, clinics used a mixture of electronic, paper, and human-based processes to manage throughput (Figure 1a). The clinic process consisted of four steps: (1) patient registration, (2) escort and pre-evaluation, (3) provider interview, and (4) check-out. Patients typically arrived in the clinic lobby before an appointment and were checked-in by clerical staff. Staff inquired about any demographic changes and then used the appointment-system software to signal patient arrival. Medical assistants (MAs) periodically checked the appointment software and escorted new patient arrivals to an exam room for an abbreviated interview. The MAs solicited a chief complaint, completed an electronic health prevention questionnaire, and measured vital signs. The MAs entered all information into a clinic "Health Promotion" note and notified the provider. It was the provider's responsibility to review medications, document new changes, address patient medical complaints, and complete health maintenance and illness management tasks.

In summary, each clinic step was person-dependent and siloed, with little emphasis on team-oriented management or shared performance. Providers shouldered a disproportionate amount of the administrative and cognitively complex clinical tasks. 


\subsection{Development of Medication Reconciliation Kiosk and Clinic Process Redesign}

The PVAMC Informatics Division developed a patient-facing self-service kiosk to support patient medication review. Although providers can collect a medication history, it can be challenging to operationalize across a healthcare facility for several reasons, including: (1) patients cannot always provide a reliable medication history, (2) compiling a list of medications from several sources is time consuming, and (3) MR may not be prioritized above competing clinical agendas [34, 60, 61]. Clinic observations and chart reviews conducted by local compliance departments showed that workflow processes were inconsistent and failure-prone. For example, chart reviews indicated that providers failed to document MR tasks in greater than $30 \%$ of all encounters [62]. Consequently, our team developed a check-in kiosk to create a standarized and reliable way to administer a medication review questionnaire. At the outset, it was unknown whether patients could complete an electronic medication questionnaire or if kiosk transaction times would bottleneck clinic throughput.

Our performance improvement team, which consisted of three medicalinformaticians, two technology specialists, and four business analysts, sought to integrate a medication history kiosk into the existing clinic workflow. The team hypothesized that a kiosk offered several potential advantages over usual care models for medication review, including (1) kiosk software could collect a history before the patient entered the exam room, (2) the software might improve patient medication recognition by displaying pharmaceutical images, (3) the software could improve the error-prone task of medication list compilation, and (4) the software would automate some chart documentation. We suspected that many of the proposed advantages would improve clinic efficiency and increase technology adoption by patients and staff stakeholders.

The team applied business process reengineering techniques to model "as-is" systems and identify performance improvement opportunities (Figure 2). Clinical members on the team collaborated with subject matter experts to describe and understand existing processes. The team then used qualitative diagrammatic process mapping to represent key actors and business processes associated with the ambulatory encounter. Diagrammatic process mapping consists of simple diagrams intended to

\begin{tabular}{|c|c|c|c|c|c|c|c|c|c|c|c|c|c|c|c|c|c|}
\hline \multirow{2}{*}{ Task } & \multirow{2}{*}{ Task Name } & \multicolumn{3}{|c|}{ Q109 } & \multicolumn{3}{|c|}{ Q2 09} & \multicolumn{3}{|c|}{ Q309 } & \multicolumn{3}{|c|}{ Q4 09} & \multicolumn{3}{|c|}{ Q1 10} & \multirow{2}{*}{\begin{tabular}{|l|} 
Q2 10 \\
Apr
\end{tabular}} \\
\hline & & Jan & $F e b$ & Mar & Apr & May & Jun & Jul & Aug & Sep & Oct & Nov & Dec & Jan & Feb & Mar & \\
\hline 1 & Business process modeling & & & & & & & & & & & & & & & & \\
\hline 2 & Specification gathering & & & & & & & & & & & & & & & & \\
\hline 3 & Software engineering & & & & & & & & & & & & & & & & \\
\hline 4 & Software and technology piloting & & & & & & & & & & & & & & & & \\
\hline 5 & Simulation model development & & & & & & & & & & & & & & & & \\
\hline 6 & Model process amendment & & & & & & & & & & & & & & & & \\
\hline 7 & Time and motion analysis & & & & & & & & & & & & & & & & \\
\hline 8 & Model refinement and verification & & & & & & & & & & & & & & & & \\
\hline
\end{tabular}

Figure 2. Gantt chart illustrating sequence and relative duration of kiosk project tasks. 
Table 1. Application of business process analysis to optimize PVAMC as-is clinic throughput.

\begin{tabular}{|c|c|c|c|}
\hline $\begin{array}{l}\text { Problem } \\
\text { Identified }\end{array}$ & $\begin{array}{l}\text { Process } \\
\text { Optimization } \\
\text { Strategy }\end{array}$ & $\begin{array}{l}\text { Process } \\
\text { Intervention }\end{array}$ & $\begin{array}{l}\text { Technology } \\
\text { Intervention }\end{array}$ \\
\hline $\begin{array}{l}\text { Check-in bottlenecks } \\
\text { caused by patient-staff } \\
\text { ratios }\end{array}$ & $\begin{array}{l}\text { Increase concurrency } \\
\text { of activities }\end{array}$ & $\begin{array}{l}\text { Multiple patients } \\
\text { to check-in } \\
\text { simultaneously }\end{array}$ & $\begin{array}{l}\text { Install multiple parallel } \\
\text { kiosks }\end{array}$ \\
\hline $\begin{array}{l}\text { Patients forget to } \\
\text { bring medication lists } \\
\text { to clinic }\end{array}$ & $\begin{array}{l}\text { Improve information } \\
\text { accessibility }\end{array}$ & $\begin{array}{l}\text { Give patients } \\
\text { medication names } \\
\text { and pictures }\end{array}$ & $\begin{array}{l}\text { Kiosks display } \\
\text { prescription names and } \\
\text { pictures }\end{array}$ \\
\hline $\begin{array}{l}\text { Patients wait to be } \\
\text { called to an exam } \\
\text { room }\end{array}$ & $\begin{array}{l}\text { Optimize activity } \\
\text { workflow }\end{array}$ & $\begin{array}{l}\text { Complete medication } \\
\text { adherence survey in } \\
\text { waiting room }\end{array}$ & $\begin{array}{l}\text { Kiosk delivers } \\
\text { medication survey }\end{array}$ \\
\hline $\begin{array}{l}\text { Providers did not } \\
\text { have time to gather } \\
\text { medication data }\end{array}$ & Simplify activities & $\begin{array}{l}\text { Assemble a composite } \\
\text { list of medications }\end{array}$ & $\begin{array}{l}\text { Software automates } \\
\text { medication retrieval } \\
\text { and display }\end{array}$ \\
\hline $\begin{array}{l}\text { Medication history } \\
\text { documentation is } \\
\text { time consuming }\end{array}$ & Combine activities & $\begin{array}{l}\text { Capture patient } \\
\text { survey responses } \\
\text { automatically }\end{array}$ & $\begin{array}{l}\text { Kiosk-collected survey } \\
\text { automatically printed } \\
\text { to the electronic record }\end{array}$ \\
\hline $\begin{array}{l}\text { Providers completing } \\
\text { administrative tasks }\end{array}$ & $\begin{array}{l}\text { Maximize staff } \\
\text { member roles }\end{array}$ & $\begin{array}{l}\text { Automate medication } \\
\text { history collection } \\
\text { and documentation }\end{array}$ & $\begin{array}{l}\text { Kiosks administer and } \\
\text { archive medication } \\
\text { adherence survey }\end{array}$ \\
\hline
\end{tabular}

depict business workflow, the key actors in the activity system, and any important tools or artifacts supporting processes [49, 63-65]. Using business process reengineering techniques, we then analyzed process patterns and subtasks for the purposes of eliminating unnecessary steps, consolidating related activities, removing bottlenecks, and simplifying steps $[63,66,67]$. The weak processes identified during this analysis are listed in Table 1.

The team worked with national medication safety specialists to develop the APHID architecture. A detailed review of the technology is beyond the scope of this paper; readers are directed to a recent implementation paper published elsewhere for a more extensive discussion [68]. Briefly, the software executable consists of a patient-facing graphic user interface (GUI), several logic modules, and a VistA database interface. The patient-facing display integrates patient data from VistA and digital pictures stored on a separate server. The APHID software acts like an integration engine, pairing pharmaceutical images with prescriptions stored in VistA (Figure 3).

The team re-designed the business process, integrating APHID technology at several administrative and clinical process points (Figure 1b, Table 1). Our aim was to generate alternative business processes addressing each of the problems identified during the process re-engineering step. Each patient must authenticate his or her identity by 


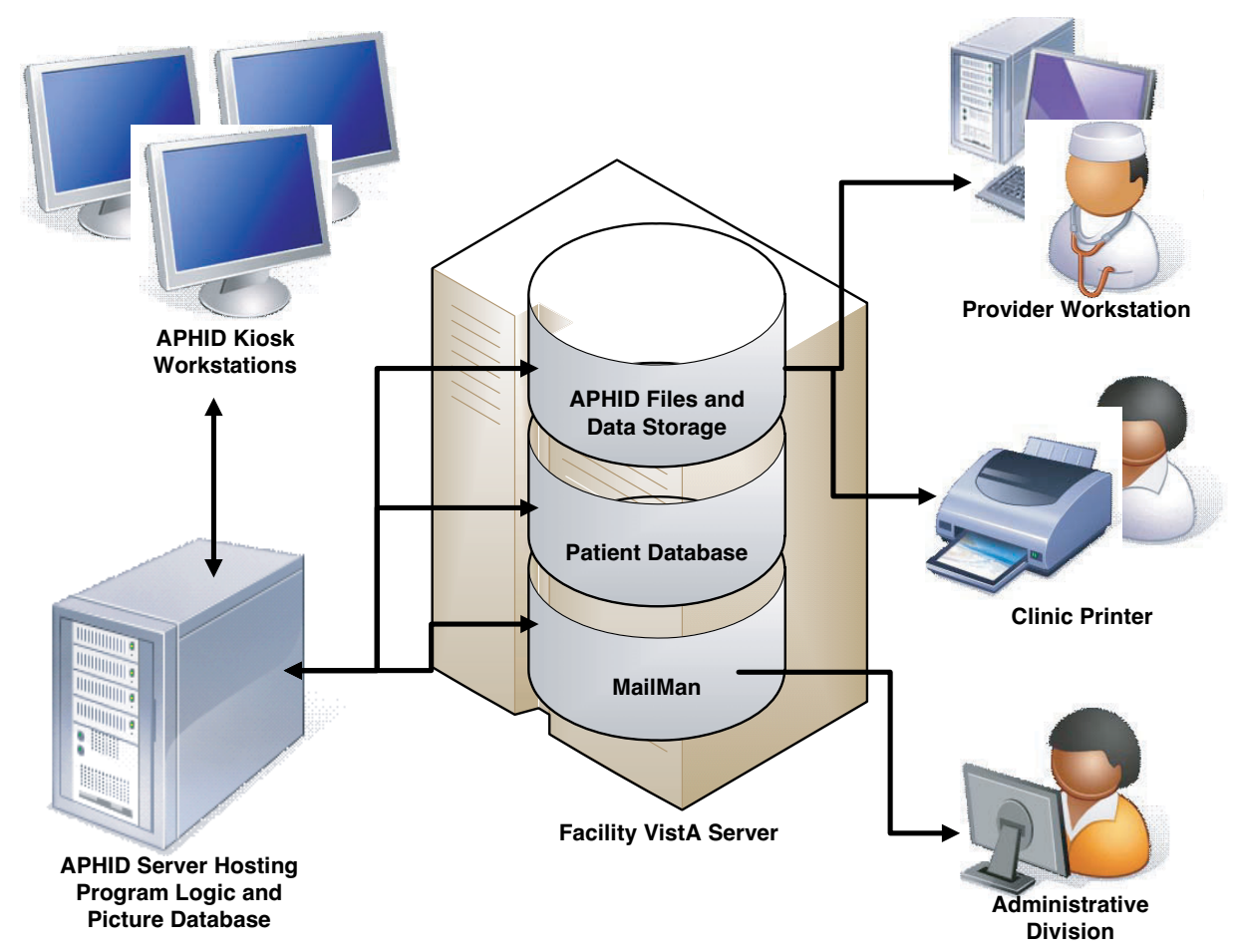

Figure 3. Schematic of the APHID system technology architecture.

swiping an identification card or answering a series of challenge questions. The patient can then use the GUI to check in for a clinic appointment and update demographic information using a combination of web control buttons, free-text dialog boxes, and a touch-responsive monitor (Figure 4). The software collects an abbreviated clinical history, reviews medication allergies, and administers a medication compliance survey.

The program retrieves prescriptions stored in VistA pharmacy files and displays the information on screen with the corresponding image (Figure 5). The patient verifies compliance with each medication using web-screen buttons. The survey asks about medications prescribed by any VA facility, previously documented non-VA medications, and recently expired prescriptions or discontinued medications. Patients are also asked about any over-the-counter medications, dietary supplements, and new prescriptions written by non-VA providers (Figure 6). At the conclusion of the session, the patient is directed to the clinic waiting area.

Data gathered by the kiosk is stored in VistA and triaged to the appropriate enterprise location according to information type (Figure 3). The VistA mail exchange system securely transmits demographic information to the enrollment department and insurance information to the billing department. Our boilerplated CPRS "Health Promotion" notes were revised to include the allergy and medication compliance output. 


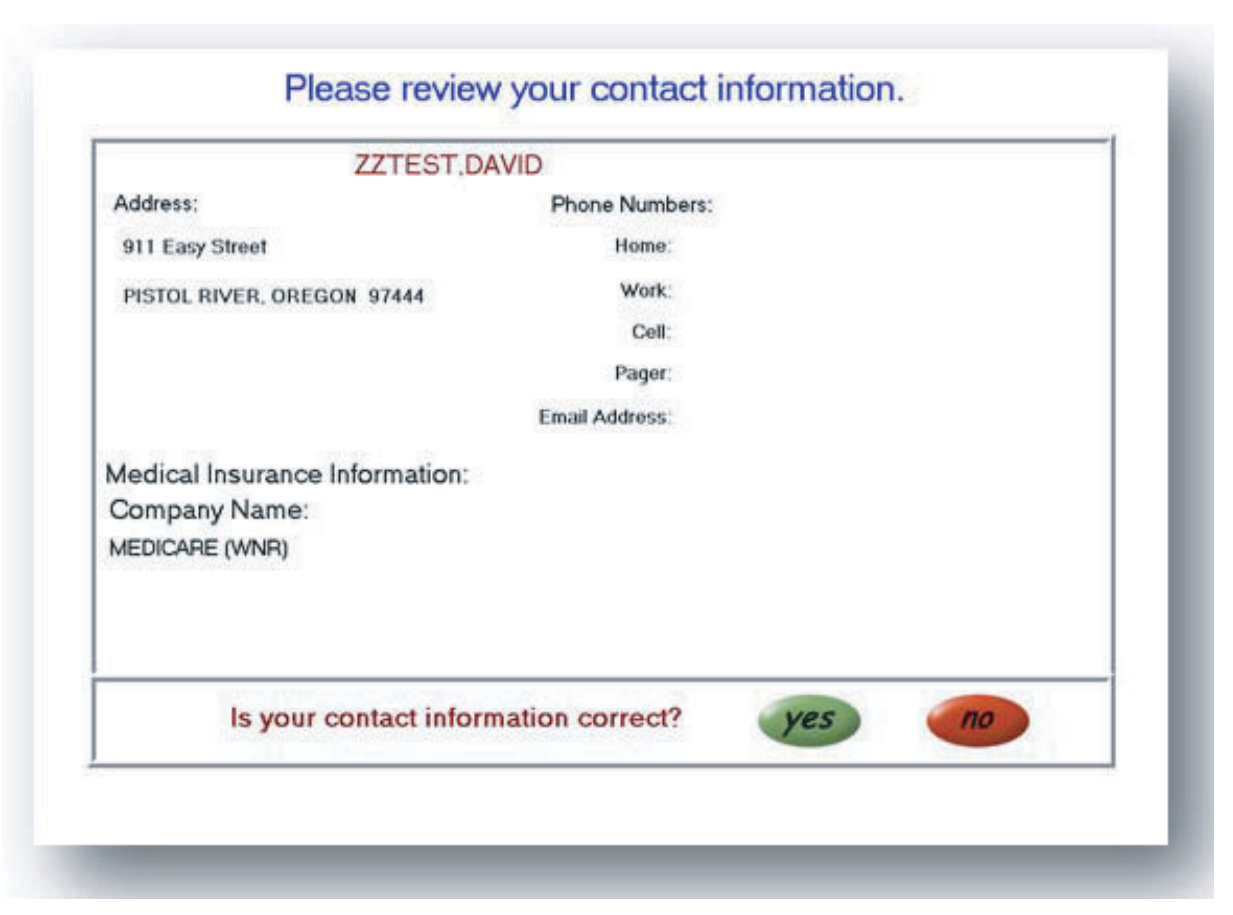

Figure 4. Screenshot of the APHID demographics verification module.

The software includes configurable "guardrail" logic intended to prevent patient check-in "bottlenecking" (Figure 7). Patients arriving before their scheduled appointment time may complete all functional modules. If a patient starts a session at the scheduled appointment time, the kiosk will check the patient in, but not run the additional modules. This feature limits patient intake delays. If the patient arrives past the appointment time, the software disallows check-in and redirects the patient to a clerk for assistance.

\subsection{Methods for Data Collection and Simulation Modeling}

The objective of simulation modeling was to estimate the number of APHID kiosks needed based on patient arrival, number of tasks, and cycle-times. The team secured Institutional Review Board exemption to collect and report data as part of a quality improvement initiative. The modeling was completed in several steps (Figure 2). First, our APHID system was implemented as a pilot project. Four kiosks were installed and permitted to run until a workflow "steady-state" was reached. This permitted the team to observe workflow and identify important workaround or recovery processes that evolved over time. Second, the team worked with simulation software to model the normative workflow path and the APHID functional modules. Third, observed ad-hoc processes were included in the simulation model. Fourth, subject matter experts reviewed and validated model design. Fifth, the team collected cycle-time data for 


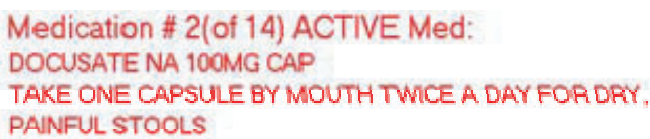

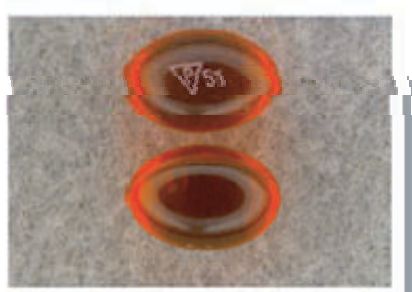

Taking this medication as directed?

$$
\text { Yes, taking as written above }
$$

Last Med

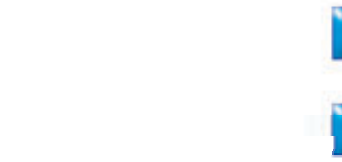

No, taking differently

No, NOT taking

\section{Unsure}

Figure 5. Screenshot of the APHID medication reconciliation module.

patients using the technology. Finally, this data was entered into the model to define stochastic behaviors for each process.

We deployed thirty-two kiosk workstations in primary and specialty care clinics throughout the medical center. During an initial prototype pilot in 2007, we empirically determined that most primary care clinics required between 2 to 4 terminals to avoid patient check-in bottlenecks. The team gathered data for the model at our Portland campus clinic, a mixed primary care and specialty care setting hosting up to 35 concurrent providers, a group education classroom, and a phlebotomy lab. The clinics share a common lobby equipped with four 0.9 meter by 1.2 meter cubicles fitted with self-service kiosks. Across from the cubicles are two manned clerical stations (Figure 8). All clinics except phlebotomy and the multidisciplinary pain clinic use APHID for check-in. The pain clinic uses a unique pre-registration process requiring administration of multiple psychometric instruments.

The team modeled APHID as a discrete event simulation in Imagine That Inc.'s ExtendSim simulation package (Figures 9-10) [69]. The use of discrete simulation models is well documented as a viable approach for representing patient arrivals in the clinical environment [70-72]. The team modeled patient arrival and flow through the clinic process using simulation software logic and used built-in software modules to represent APHID functional components. Initially, we mapped primary flow to ensure 


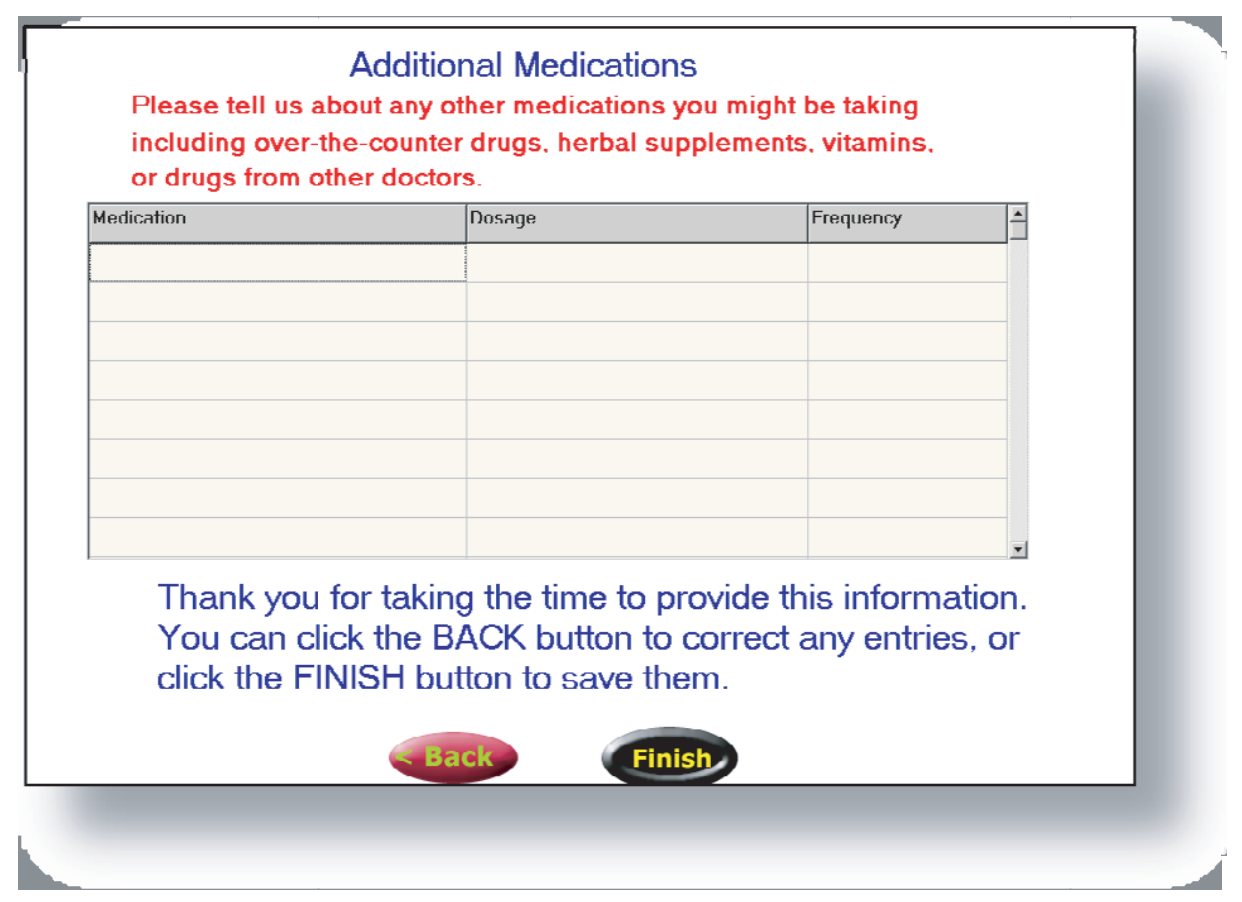

Figure 6. Screenshot of the APHID medication addition module.

that a deterministic (i.e., single flow path) event pattern would align with correct logic pathways of the model. Next, we added alternate paths, including patient work-arounds and staff recovery steps, to represent uncertain events, possible choices, or observed behaviors.

After the first round of model construction was complete, designers of the APHID system reviewed and verified logical flow and function. This allowed simulation of the entire patient experience, including non-deterministic human behaviors. As with any simulation modeling effort, the model was not a $100 \%$ replica of the APHID software or its functional logic, but a model of the pertinent patient activities that would influence (a) usage of the system, (b) potential flow delays, and (c) queuing impact.

The team collected cycle-time data on patients using the production system to inform simulation model design. The study team developed a time-and-motion data collection form and monitored 100 sequential patient arrivals in a series of observation sessions , each lasting approximately one-half day (e.g., 9:30 am - 12:00 pm), and conducted over a two-week interval. This permitted the team to track wait times at the terminals in the context of a typical workday. Study team members recorded the time required to begin each kiosk session and the time required to complete each functional module. The team also recorded when guardrail logic was invoked, if the patient abandoned a session, and 


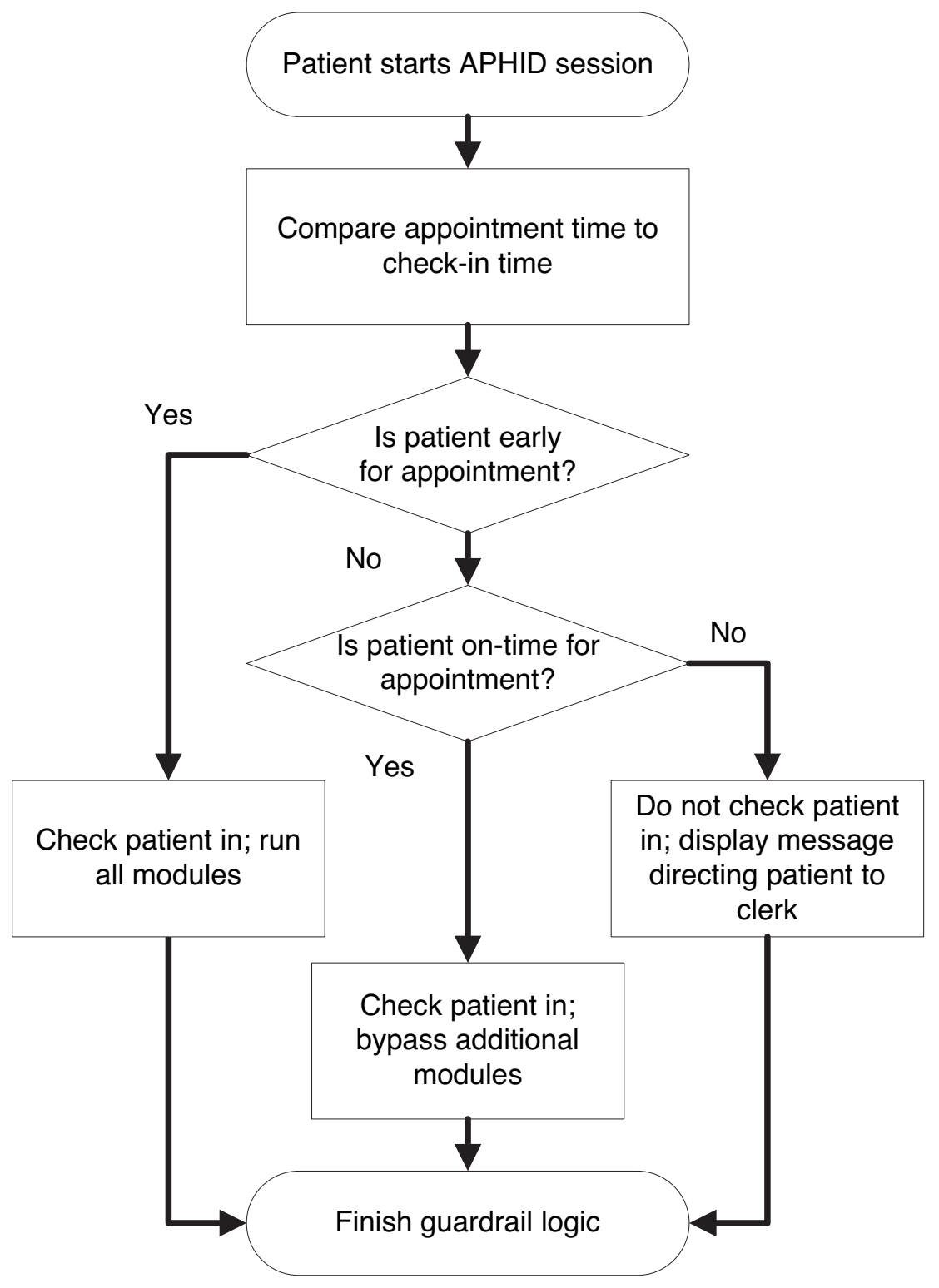

Figure 7. Guardrail software logic intended to limit patient bottlenecking.

if any staff assistance was required. The team recorded the number of medications reviewed or added, the type of clinic appointment, and the age of each subject. The information collected helped to determine stochastic behaviors influencing the primary model output. 


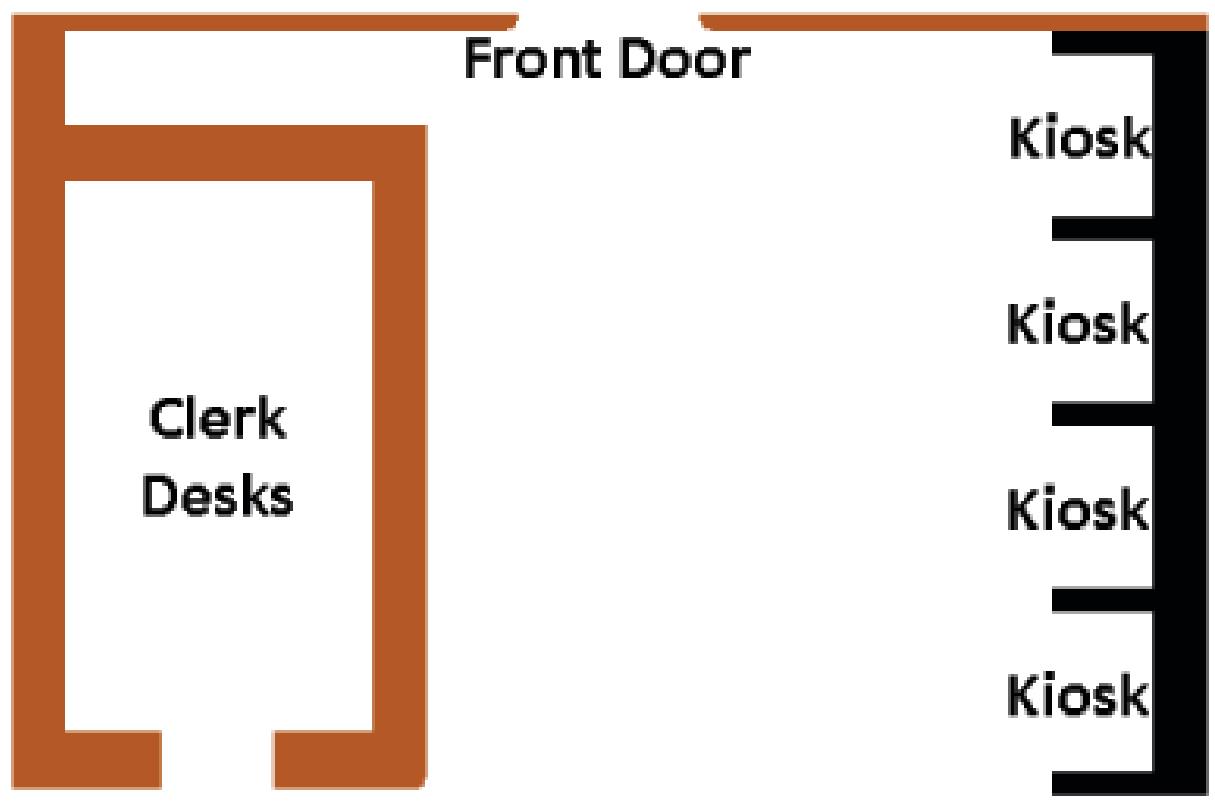

\section{<-- To Waiting Rooms -->}

Figure 8. Schematic of the APHID kiosk installation in a multi-clinic lobby. Because kiosks were positioned across from clerical workstations, patients naturally gravitated to the clerks and had to be encouraged to use the workstations. It was also more difficult for staff to proctor kiosk terminals.

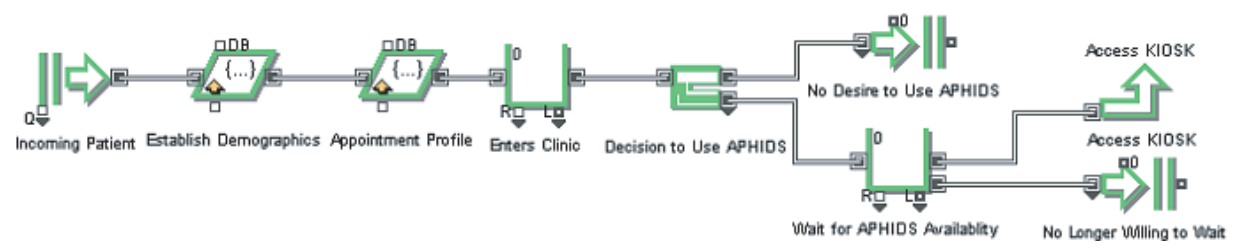

Figure 9. Simulation model for kiosk approach (i.e., entering standard check-in pathway) designed using a commercial software [69]. 

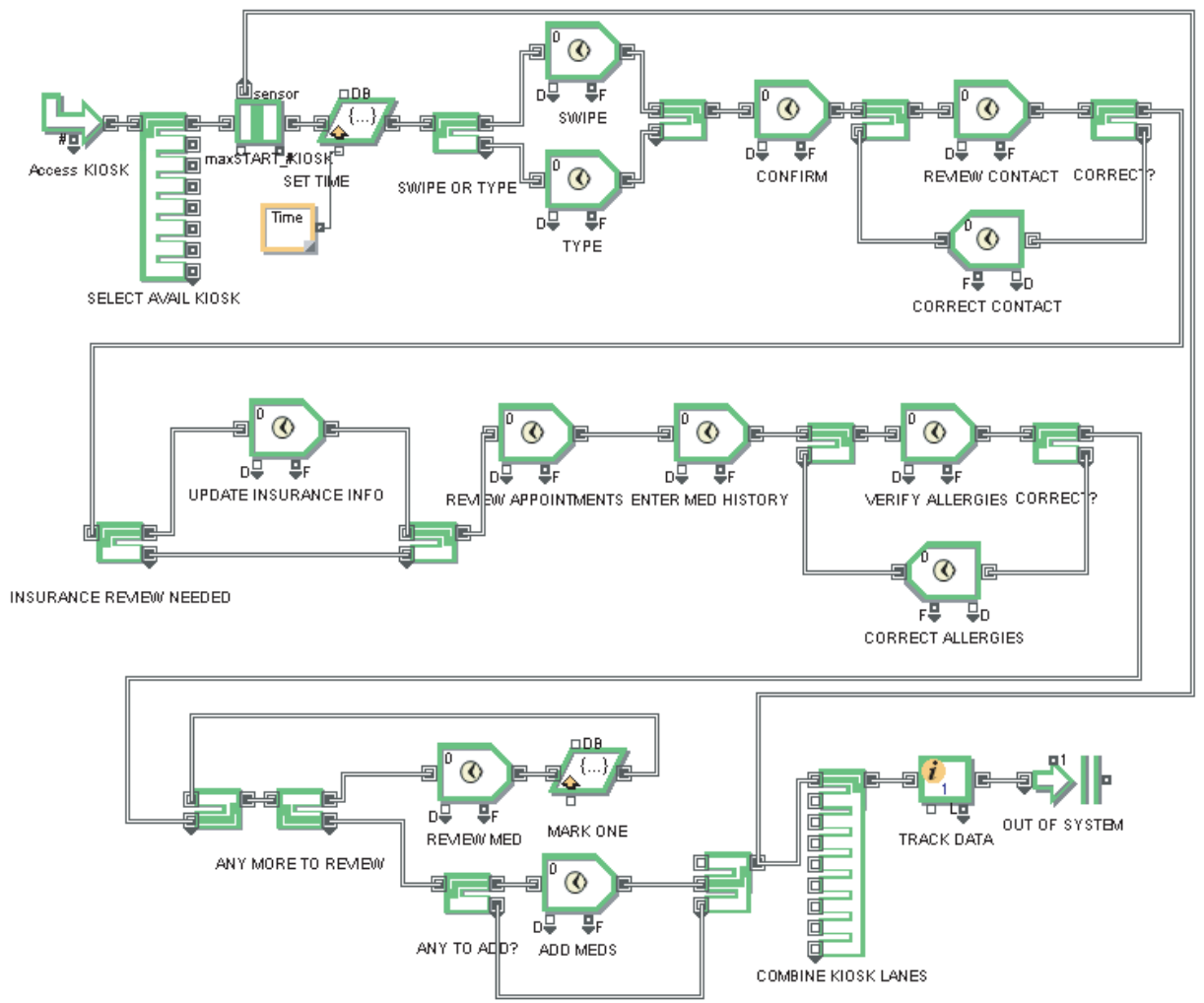

Figure 10. Simulation model for patient kiosk process use designed using a commercial software [69].

Finally, we added cycle time data to the model and attached the patient demand pattern (i.e., non-linear arrival rate) to the primary event generator. Patient demand patterns are important for the model since they drive system use.

\subsection{Process Validation}

The project team verified model behavior through logic reviews, temporary conversion of stochastic behaviors to deterministic ones in order to ensure proper model behavior, and singular entity trace paths through the model. The simulation model was not complex since it considered mainly entity flow and capacity. This allowed the use of manually generated flow confirmation and did not require the use of automated verification techniques.

Validation of the model initially was done through the comparison of the daily flow data collected at the site and a review of the model flow animations with the project team. As the model gains usage, we hope to make refinements based on observed variation in patient behavior and be able to incorporate more granular detail about patient characteristics such as educational status, computer literacy, and number and 
Table 2. Descriptive variables for patient sample.

\begin{tabular}{lcc}
\hline Descriptive variables & $\mathbf{n}$ & $\mathbf{\%}$ \\
\hline Total sample size & 100 & \\
Total number of patients that entered kiosk pathway & 88 & 3 \\
Check in not permitted & 3 & 15 \\
Check in only permitted & 13 & 78 \\
All modules permitted & 69 & 3 \\
Check in and demographics completed & 3 & \\
Total number of patients used for simulation modeling & 56 & \\
Magnetic stripe swipe rate (\%) & 81 & \\
Guardrail logic invoked (\%) & 40 & \\
Proctor assisted with check in processes (\%) & 7 & \\
\hline
\end{tabular}

type of comorbidities. The use of a dynamic modeling environment allows new data to be included in the model if the output begins to drift from actual experience.

\section{RESULTS}

The project team used 88 of the 100 total cases observed to calculate descriptive and use statistics (Table 2, Figure 11). We excluded 12 cases from analysis where patients

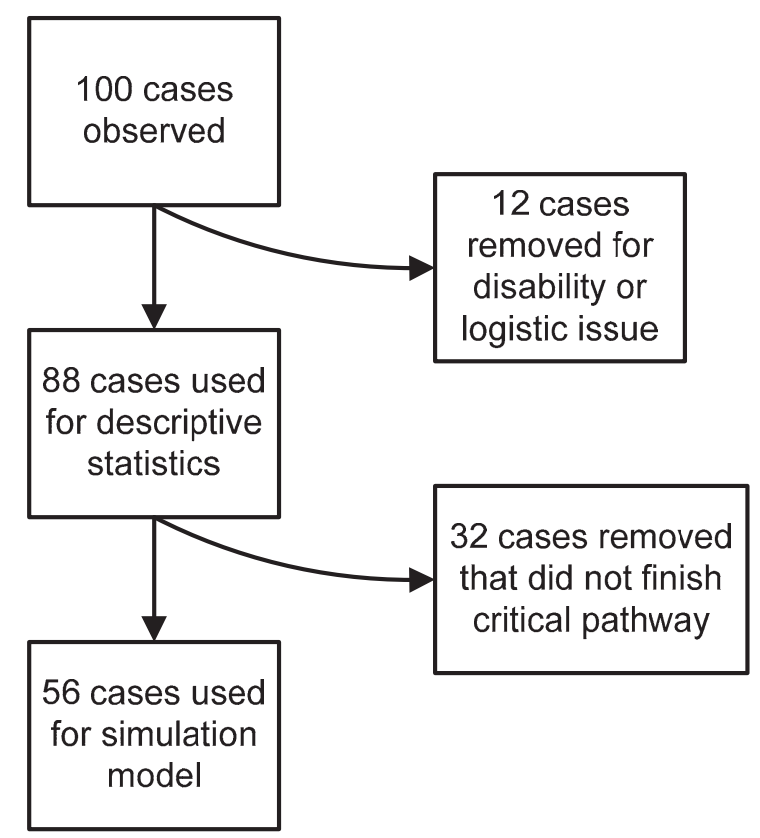

Figure 11. Sample inclusion and exclusion descriptive statistics. 
were unable to use the kiosk because of disability (e.g., severe cognitive, neuromuscular, or visual impairment) or a clinic logistic issue (e.g., patient presenting for a phlebotomy drop-in appointment). The team used $56(63 \%)$ of the remaining 88 cases to generate simulation model calculations because these patients completed every kiosk functional module. The 32 excluded patients did not complete one or more of the kiosk modules for one of several reasons, including (1) lack of time, (2) clinic check-in configuration, and (3) patient abandonment. Hence, the model is conservative and likely under-estimates the true kiosk capacity. The average patient age was 60.3 years old $(6>75 y ; 8 \%)$. The average number of medications reviewed was 16 (range $0-56$ ). It is important to note that many of the medications reviewed represented expired or discontinued prescriptions not currently taken by the patient.

Empiric data collected from patient observations suggests that patients spent a modest amount of time entering or reviewing information at the kiosk in relation to typical clinic appointment wait times (Table 3, Figures 12-16). Patients completing all functional modules spent an average of 3.55 minutes (maximum of 12.8 minutes) at the kiosk and an average of 1.67 minutes (maximum of 4.67 minutes) reviewing medication information (Figure 12). These values approximate previously published cycle-times for patients' use of a healthcare kiosk [68]. It is important to note that the

Table 3. Descriptive statistics for module completion cycle times.

\begin{tabular}{|c|c|c|c|c|c|c|c|}
\hline & $\mathbf{n}$ & $\%$ & $\begin{array}{l}\text { Total } \\
\min \end{array}$ & $\begin{array}{l}\text { Avg } \\
\text { min }\end{array}$ & $\begin{array}{l}\text { Std } \\
\text { Dev }\end{array}$ & Mode & $\begin{array}{c}\text { Max } \\
\min \end{array}$ \\
\hline \multirow{4}{*}{$\begin{array}{l}\text { Time arrived prior to scheduled } \\
\text { appointment }\end{array}$} & 69 & & $>3$ & & & & \\
\hline & 3 & & $3-0$ & & & & \\
\hline & 13 & & 0-10 late & & & & \\
\hline & 3 & & $>10$ late & & & & \\
\hline \multirow{4}{*}{$\begin{array}{l}\text { Time from arrival to beginning of } \\
\text { APHID check in }\end{array}$} & 3 & & $>3$ & & & & \\
\hline & 1 & & $3-2$ & & & & \\
\hline & 9 & & $2-1$ & & & & \\
\hline & 75 & & $<1$ & & & & \\
\hline $\begin{array}{l}\text { Time to complete demographics } \\
\text { module }\end{array}$ & 56 & & & 0.43 & 0.47 & .08 & 1.27 \\
\hline $\begin{array}{l}\text { Time to complete allergy review } \\
\text { module }\end{array}$ & 56 & & & 0.37 & 0.41 & 0.03 & 1.58 \\
\hline $\begin{array}{l}\text { Time to complete medical history } \\
\text { module }\end{array}$ & 56 & & & 0.34 & 0.53 & 0.08 & 3.48 \\
\hline $\begin{array}{l}\text { Time to complete medication history } \\
\text { module }\end{array}$ & 56 & & & 1.66 & 1.17 & 1.33 & 4.67 \\
\hline $\begin{array}{l}\text { Time to complete medication addition } \\
\text { module }\end{array}$ & 56 & & & 0.74 & 1.40 & 0.08 & 7.83 \\
\hline
\end{tabular}




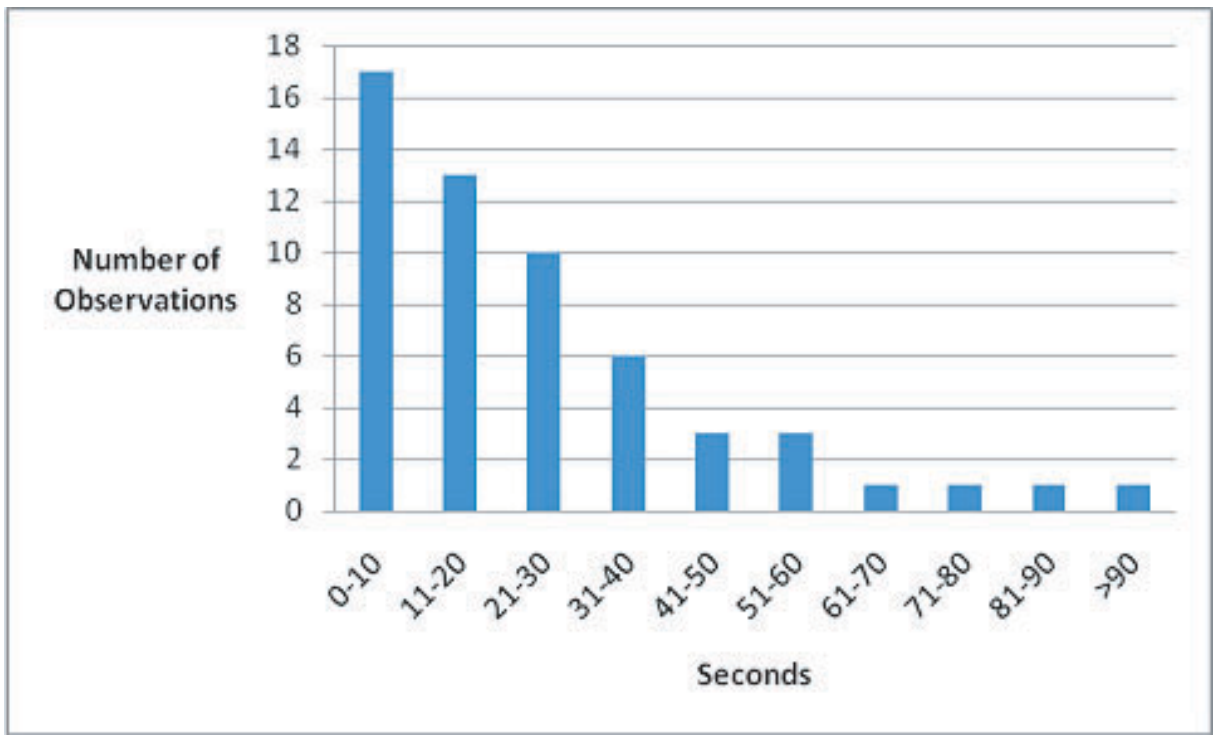

Figure 12. Time distribution for patient completion of demographics module. Data gathered during direct patient observation.

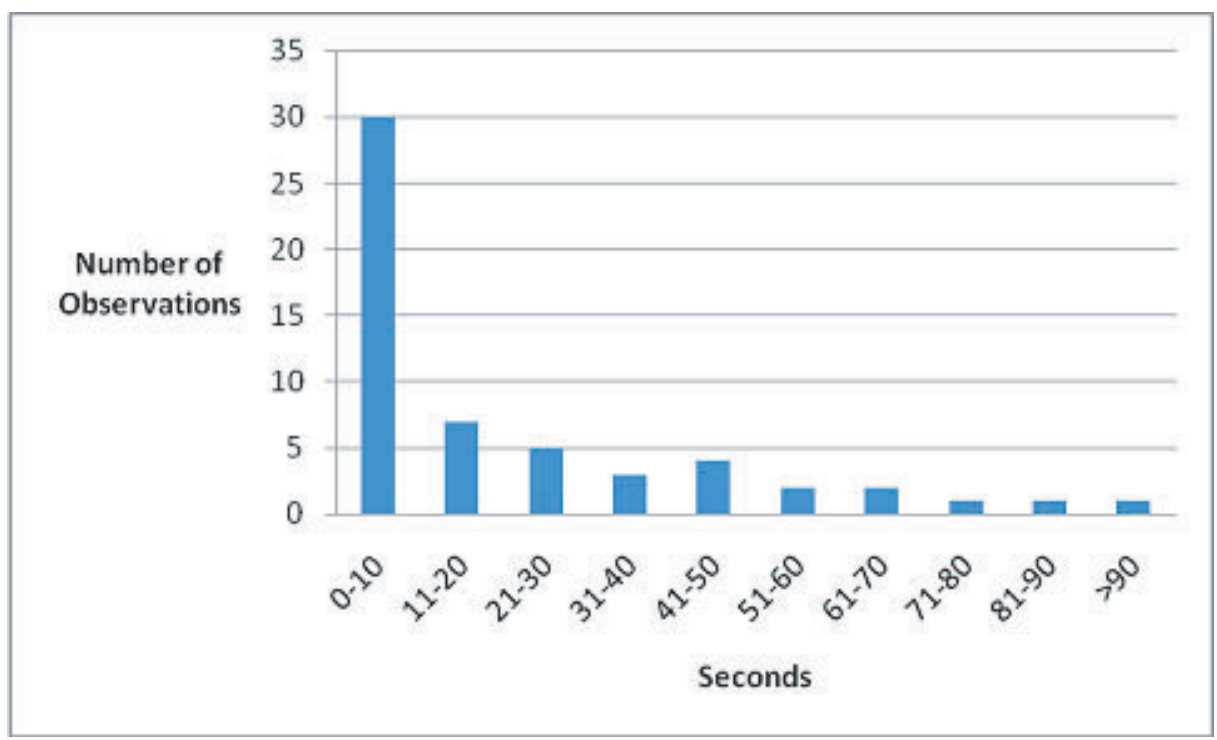

Figure 13. Time distribution for completion of allergy module. Data gathered during direct patient observation. 


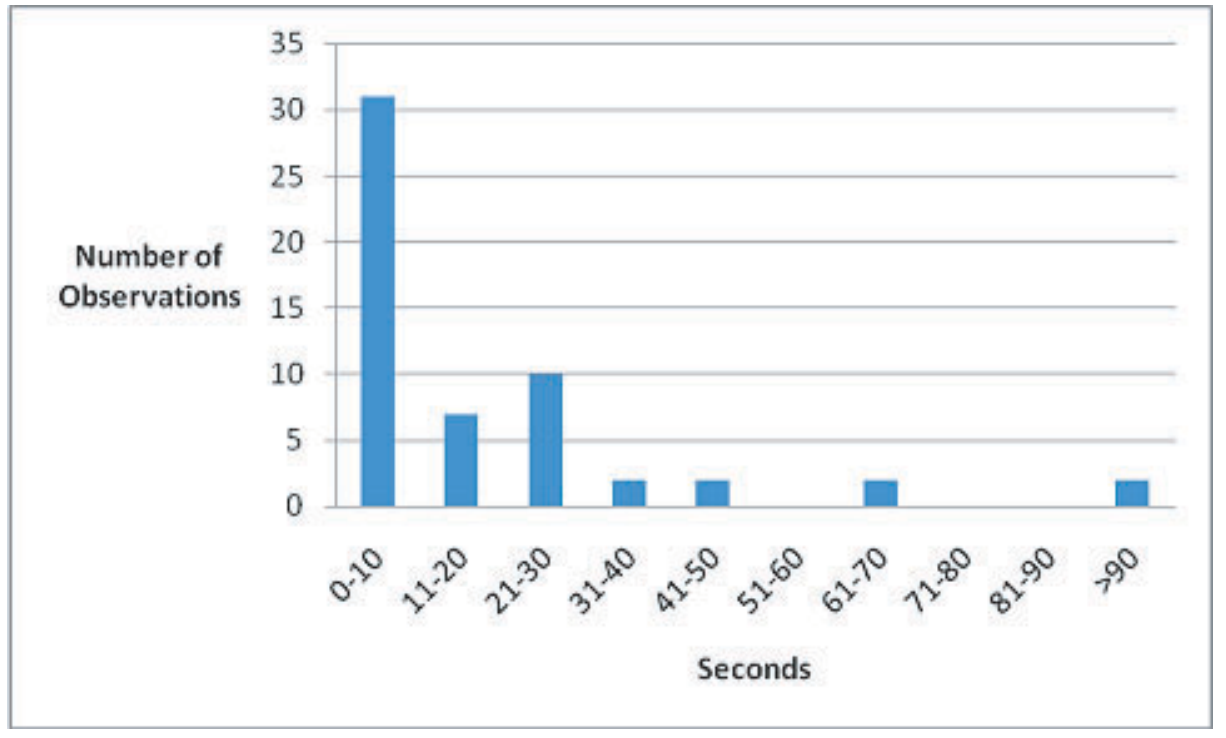

Figure 14. Time distribution for patient completion of medical history module. Data collected during direct patient observation.

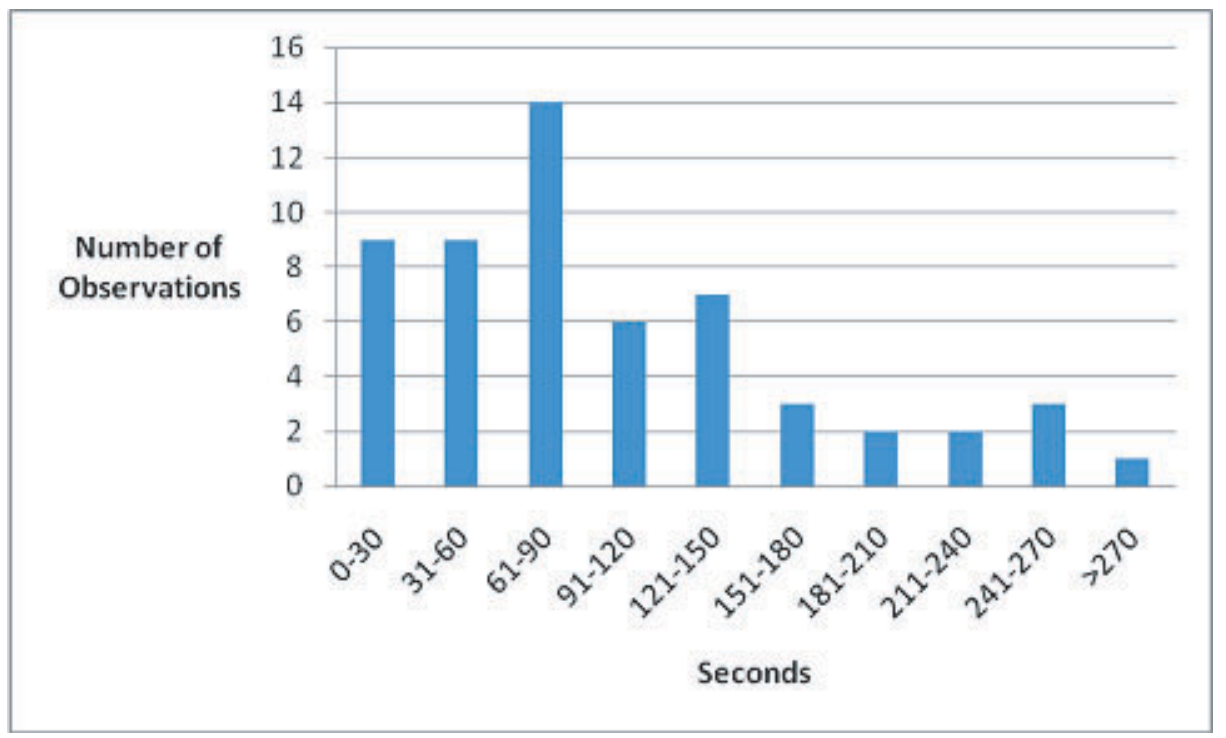

Figure 15. Time distribution for completion of medication list review module. Data collected during direct patient observation. 


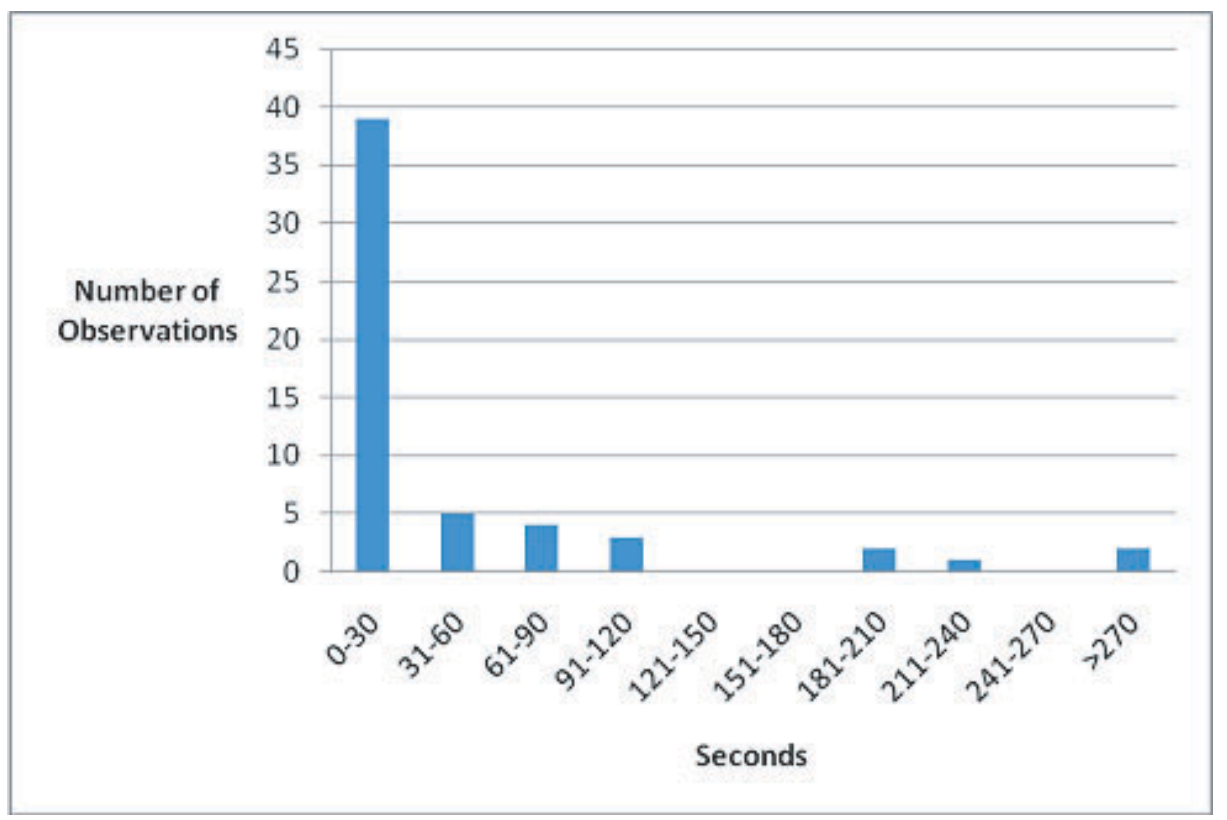

Figure 16. Time distribution for patient completion of medication addition module. Data collected during direct patient observation. Most patients did not need to key-enter new medications and simply indicated "no changes".

distribution of recorded cycle times for each module was non-Gaussian. The majority of patients completed each module in less than average time.

The team completed simulation scenarios while varying the patient arrival patterns (Table 4). The first scenario was based on the arrival rate captured during empiric data collection and converted to stochastic distributions (not a static fixed inter-arrival rate) for use in the simulation model. We pulled samples from an exponential distribution based upon the mean time between arrivals. Furthermore, all parameters used in the model are representative of stochastic distributions based upon observation data. We conducted the simulation scenarios multiple times (Table 4) and gathered statistics on the average time-weighted patient queue wait times for each run. A simulation represented a full 8-hour day with a stable exponential rate of inter-arrival times throughout the day. We adjusted the number of simulation runs in each scenario to achieve a relative confidence error (at the $95 \%$ level) of less than $5 \%$.

The simulation output is typical of queuing systems in which a single kiosk addition or subtraction, or an increase or decrease in the arrival rate, results in a non-linear change in the wait times. Patients can expect to wait an average of 3.4 seconds to use a kiosk terminal in a clinic equipped with two kiosks and seeing approximately 25 patients per hour. These results approximate the expected throughput for a single clinic or department. However, patients may expect to wait an average of 30 minutes at facilities consolidating check-in capabilities at one location equipped with three kiosks and processing 
Table 4. The simulation average wait times based on patient arrival rate and number of kiosks.

\begin{tabular}{lcccccc}
\hline Simulation & $\mathbf{1}$ & $\mathbf{2}$ & $\mathbf{3}$ & $\mathbf{4}$ & $\mathbf{5}$ & $\mathbf{6}$ \\
\hline Number of kiosks & 1 & 1 & 2 & 2 & 3 & 3 \\
Mean time between patients (s) & 288 & 144 & 144 & 72 & 72 & 36 \\
Patients per hour & 12.5 & 25 & 25 & 50 & 50 & 100 \\
Number of simulation runs & 924 & 924 & 739 & 841 & 421 & 124 \\
Mean wait time (sec) & 10.3 & 216.6 & 3.4 & 114.6 & 5.4 & 1827.3 \\
Std dev wait time & 7.6 & 159.7 & 2.2 & 80.6 & 2.7 & 488.3 \\
95\% CI & 0.5 & 10.3 & 0.2 & 5.4 & 0.3 & 86.8 \\
Relative CI error & 0.048 & 0.047 & 0.047 & 0.048 & 0.048 & 0.048 \\
\hline
\end{tabular}

approximately 100 patients an hour. Hence, facilities consolidating pre-registration tasks in a centralized location would need more terminals to handle a higher patient volume.

\section{DISCUSSION}

The observational data and simulation output provide important time-and-motion information about patient use of a healthcare kiosk. In general, veteran patients were able to complete several administrative and clinical transactions at a self-service kiosk during time otherwise wasted in the clinic waiting room. This should disabuse critics of the misconception that healthcare kiosks are too complicated for patients to use or that kiosks invariably halt clinic throughput. Our findings suggest that kiosks, if thoughtfully integrated into business workflow, can help with important clinic data collection tasks and improve patient processing wait times. Many patients were able to complete complex cognitive tasks including prescription review and new medication information entry in less than four minutes.

These findings notwithstanding, it is critical to emphasize that approximately $37 \%$ of the patients did not complete one or more modules in the pathway as a result of intended business engineering (e.g., guardrails). Approximately 5\% of the patients were cognitively or physically impaired and required the assistance of a staff member to complete a compliance history. Other patients arrived too late for check-in or asked to see a clerk for other needs. These patients still had to complete similar pre-registration steps. Hence, recovery processes were created and integrated into clinic staff job expectations.

Furthermore, we previously reported that patients were able to understand and use the software with minimal assistance. Yet, we received mixed satisfaction feedback from patients during our time-and-motion data collection. Some disliked using a computer rather than interacting with a clerk whereas others were disinclined to complete the medication adherence survey when "the clinic already has the information on record". These findings draw attention to the reality that self-service kiosks do not simply replace clerks and medical personnel, and should not be installed in isolated locations or left unattended. Like other industries, kiosks are more likely to be successful if proctored by staff and marketed appropriately [43]. Staff must engage 
patients, emphasize task importance, and assist with patient concerns including wayfinding, medical questions, or other administrative tasks.

Although kiosks have not replaced clerks at our facility, they provide a costeffective method to augment current staffing. For example, an MA can check in one patient and gather an abbreviated medication history every 8-10 minutes, whereas one MA can proctor four workstations and complete the same number of tasks for four patients in under four minutes. The average annual salary for an MA is $\$ 45,500$ and each kiosk represents a one-time cost of approximately $\$ 2,000$ plus $\$ 6000$ for the cost of a server, making this a reasonable facility investment. It is difficult, however, to estimate the cost per transaction for our model or to generalize the cost for non-VA settings since our development activities were conducted under the auspices of the VA using locally-developed software. Nevertheless, these results suggest that selfservice kiosks are a feasible model to collect information using less of the actual appointment time and can help systematize complicated or time-consuming clinical tasks, including MR.

Although we previously reported that the APHID software may offer a sensitive method for detecting medication discrepancies (4.6 discrepancies per visit $(28.5 \%) ; 1.6$ significant discrepancies per visit $(9.8 \%)$ ), it will be critical to measure the accuracy of information in comparison to high fidelity collection methods before we can advocate kiosks as a best-practice for medication information collection [73]. To this end, our team is currently studying the diagnostic performance of APHID's discrepancy detection in comparison to provider-conducted medication histories.

The simulation model provides a novel and flexible method to help healthcare executives and clinic administrators better predict the self-service technology requirements necessary to optimize clinic productivity. Healthcare systems, unlike industrial systems, are dynamic and changeful in response to the characteristics of a clinical case, setting, or patient cohort. Although these systems can be difficult to predict when introducing new technology, simulation models offer a cost-effective and agile method to evaluate healthcare environments. By feeding a modest set of observations into a simulation model, executives and systems engineers can estimate firmware needs, built-environment issues, and patient traffic flow, while avoiding unnecessary resource use or prolonged customer wait times. Likewise, clinic administrators and point-of-care providers can better predict the patient process-time impact when introducing new functional modules. Conceivably, there are a maximum number of tasks that can be added to a single session before clinics see a decrease in customer use or an increase in clinic wait times. This may become increasingly germane as kiosks begin to offer more clinical services including preventative health questionnaires, chronic illness assessment, and biometric data collection.

To our knowledge, this is only the third time-and-motion study of a healthcare kiosk and adds important information to guide future multi-functional kiosk deployments [68, 73]. We believe the next logical step is to move the model from an experimental prototype to a more robust and user-friendly version, enabling administrative staff to input patient arrival and demographic data as well as localized calibration of guardrail settings. Ideally, a well-designed user interface would present the critical data to support decision making while suppressing unnecessary complexity. 


\subsection{Limitations}

Although this application of business process reengineering narrows a literature gap on healthcare kiosk implementation, there are design considerations that may limit validity or generalizability. First, healthcare business processes are complex, often recursive, and necessarily organic to manage changes in input. Nonetheless, we intentionally simplified models to enable analysis and schematically represent key steps. Second, we collected data in a single ambulatory care installation, which may not reflect other healthcare contexts. Different patient populations, built environments, staffing models, and preregistration expectations may all have an important effect on implementation. Additional observational data should be collected to validate and refine the model. Third, it is important to recognize the shortcomings of simulation analysis. We carefully considered definition of entities, logic, and constraints. Nonetheless, differences between simulation models and real operational performance are unavoidable. Fourth, we only included patient data in our model from subjects completing all functional modules. This created a conservative "worst-case scenario" estimate of kiosk throughput and likely underestimates the actual capacity of the model. Fifth, Walston correctly noted that a variety of sociotechnical factors (e.g., power relationships, project teams, executive involvement) positively or negatively moderate the effects of re-engineering [74]. Our models do not capture the coexistent moderating sociotechnical covariates that may have influenced our implementation. Finally, further multi-modal evaluation using rigorous methodology is necessary. We are presently gathering metrics that examine concepts of data validity, organizational quality performance, and user satisfaction.

\section{CONCLUSION}

Healthcare facilities are increasingly exploring self-service software to expand the array of organizational service offerings to the care consumer. In circumstances where the time pressures of the ambulatory setting demand novel strategies to engage patients, kiosks offer the dual promise of improved efficiency and patient-centric care. Nonetheless, very little evidence exists to support the rational implementation of kiosk technology. As a result, clinics rely on ad hoc methods to estimate resource needs and calculate staffing.

We believe this report fills an important gap in the informatics literature. Our preliminary findings suggest that a multi-function healthcare kiosk can complete a number of clinical transactions without negatively affecting clinic throughput. Furthermore, prediction tools such as discrete event simulation may help guide kiosk deployment by estimating patient load and registration queues. This modeling approach potentially provides a low cost, low risk strategy to test incremental process improvements or to forecast large-scale re-engineering initiatives. Further testing and external validation of the approach are needed, including evaluation of other kiosk services, testing in different healthcare settings, and validation with larger patient observation samples.

\section{ACKNOWLEDGEMENTS}

This work was supported in part by the Portland VA Medical Center Technology and Information Management Section, the Portland VA Office of Systems Engineering, the VA Chief Business Office, the Portland VA Research Division, and the VA National Center for Patient Safety. The authors wish to thank our peer reviewers for their insightful and constructive feedback. 


\section{REFERENCES}

[1]. The Institute of Medicine. Preventing Medication Errors. Washington DC: National Academy of Sciences; 2006.

[2]. Bates D, Spell N, Cullen D, Burdick E, Laird N, Petersen L, et al. The costs of adverse drug events in hospitalized patients. Adverse Drug Events Prevention Study Group. Journal of the American Medical Association. 1997;277(4):307-11.

[3]. Hasan S, Duncan G, Neill D, Padman R. Towards a collaborative filtering approach to medication reconciliation. AMIA Symposium Proceedings. 2008:288-92.

[4]. Pronovost P, Weast B, Schwarz M, Wyskiel R, Prow D, Milanovich S, et al. Medication reconciliation: A practical tool to reduce the risk of medication errors. Journal of Critical Care. 2003 December;18(4):201-5.

[5]. Pippins J, Gandhi T, Hamann C, Ndumele C, Labonville S, Diedrichsen E, et al. Classifying and predicting errors of inpatient medication reconciliation. Journal of General Internal Medicine. 2008;23(9):1414-22.

[6]. Santell J. Reconciliation failures lead to medication errors. Joint Commission Journal on Quality and Patient Safety. 2006;32(4):225-9.

[7]. Vira T, Colquhoun M, Etchells E. Reconcilable differences: Correcting medication errors at hospital admission and discharge. Quality and Safety in Health Care. 2006;15:122-6.

[8]. Schnipper J, Kirwin J, Cotugno M, Wahlstrom S, Brown B, Tarvin E, et al. Role of pharmacist counseling in preventing adverse drug events after hospitalization. Archives of Internal Medicine. 2006 March 13;166:565-71.

[9]. Wortman S. Medication reconciliation in a community, nonteaching hospital. American Journal of Health System Pharmacy. 2008;65(1):2047-54.

[10]. Wagner M, Hogan W. The accuracy of medication data in an outpatient electronic medical record. Journal of the American Medical Informatics Association. 1996;3(3):234-44.

[11]. Varkey P, Resar R. Medication reconciliiation implementation in an academic center. American Journal of Medical Quality. 2006 September/October;21(5):293-5.

[12]. Makaryus A, Friedman E. Patients' understanding of their treatment plans and diagnosis at discharge. Mayo Clinic Proceedings. 2005;80(8):001-994.

[13]. Orrico K. Sources and types of discrepancies between electronic medical records and actual outpatient medication use. Journal of Managed Care Pharmacy. 2008;14(7):626-31.

[14]. Staroselsky M, Volk L, Tsurikova R, Newmark L, Lippincott M, Litvak I, et al. An effort to improve electronic health record medication list accuracy between visits: Patients' and physicians' response. International Journal of Medical Informatics. 2008;77:153-60.

[15]. Friedman A, Georghegan S, Sowers N, Kulkarni S, Formica R. Medication errors in the outpatient setting. Archives of Surgery. 2007 March;142:278-83.

[16]. Bergkvist A, Midlov P, Hoglund P, Larsson L, Bondesson A, Eriksson T. Improved quality in the hospital discharge summary reduces medication errors - LIMM: Landskrona Integrated Medicines Managment. European Journal of Clinical Pharmacology. 2009;65:1037-46.

[17]. Bayoumi I, Howard M, Holbrook A, Schabort I. Interventions to improve medication reconciliation in primary care. Annals of Pharmacotherapy. 2009;43(October):1667-75.

[18]. Manno M, Hayes D. How medication reconciliation saves lives. Nursing. 2006;36(3):63-4.

[19]. Rogers G, Alper E, Brunelle D, Federico F, Fenn C, Leape L, et al. Reconciling medications at admission: safe practice recommendations and implementation strategies. Joint Commission Journal on Quality and Patient Safety. 2006;32(1):37-50.

[20]. Jack B, Chetty V, Anthony D, Greenwald J, Sanchez G, Johnson A, et al. A reengineered hospital dischage program to decrease rehospitalization. Annals of Internal Medicine. 2009;150(3):178-87.

[21]. Bails D, Clayton K, Roy K, Cantor M. Implementing online medication reconciliation at a large academic medical center. Joint Commission Journal on Quality and Patient Safety. 2008;34(9):499-508. 
[22]. Rozich J, Howard R, Justeson J, Macken P, Lindsay M, Resar R. Standardization as a mechanism to improve safety in health care. Joint commission Journal on Quality and Safety. 2004 January; 30(1):5-14.

[23]. Kramer J, Hopkins P, Rosendale J, Garrelts J, Hale L, Nester T, et al. Implementation of an electronic system for medication reconciliation. American Journal of Health System Pharmacy. 2007 February 15, 2007;64:404-22.

[24]. Boockvar K, Liu S, Goldstein N, Nebeker J, Siu A, Fried T. Prescribing discrepancies llikely to cause adverse drug events after patient transfer. Quality and Safety in Health Care. 2009;18:32-6.

[25]. Bedell S, Jabbour S, Goldberg R, Glaser H, Gobble S, Young-Xu Y, et al. Discrepancies in the use of medications. Archives of Internal Medicine. 2000 July 24;160:2129-34.

[26]. Joint Commission on Accreditation of Healthcare Organizations. Hospitals' National Patient Safety Goals. Washington DC2005; Available from: http://www.jcaho.org/accredited+organizations/patient+ safety/05+npsg/05_npsg_haphtm.

[27]. Institute of Healthcare Improvement. Protecting 5 Million Lives From Harm. Cambridge2007; Available from: http://www.ihi.org/IHI/Programs/Campaign/Campaign.htm?TabId=1.

[28]. VA National Center for Patient Safety. NCPS TIPS - January/February 2006. Washington DC2007; Available from: http://www.va.gov/ncps/TIPS/Docs/TIPS_JanFeb06.doc.

[29]. The Massachusetts Coalition. Massachusetts Coalition for the Prevention of Medical Errors. [website] Burlington, Massachusetts2007 [cited 2007]; Available from: http://www.macoalition.org/index.shtml.

[30]. Poon E, Blumenfeld B, Hamann C, Turchin A, Graydon-Baker E, McCarthy P, et al. Design and implementation of an application and associated services to support interdisciplinary medication reconciliation efforts at an integrated healthcare delivery network. Journal of the American Medical Informatics Association. 2006 Nov/Dec;13(6):581-92.

[31]. Barnsteiner J. Medication reconciliation: Transfer of medication information across settings - keeping it free from error. American Journal of Nursing. 2005 March;Supplement:31-6.

[32]. Young B. Medication reconciliation matters. MedSurg Nursing. 2008;17(5):332-6.

[33]. Clay B, Halasyamani L, Stucky E, Greewald J, Williams M. Results of a medication reconciliation survey from the 2006 Society of Hospital Medicine national meeting. Journal of Hospital Medicine. 2008;3(6):465-72.

[34]. King J, Schommer J, Wirsching R. Patients' knowledge of medication care plans after hospital discharge. American Journal of Health System Pharmacy. 1998;55:1389-93.

[35]. Cornish P, Knowles S, Marchesano R, Tam V, Shadowitz S, Juurlink D, et al. Unintended medication discrepancies at the time of hospital admission. Archives of Internal Medicine. 2005;165(Feb 28):424-9.

[36]. Bridgeman P, Rynn K. Medication reconciliation in the emergency department. American Journal of Health System Pharmacy. 2008 December 15;65:2325-6.

[37]. Gleason K, Groszek J, Sulllivan C, Rooney D, Barnard C, Noskin G. Reconciliation of discrepancies in medication histories and admission order of newly hospitalized patients. American Journal of Health System Pharmacy. 2004 August 15;61:1689-95.

[38]. Mersfelder T, Bickel R. Inpatient medication history verification by pharmacy students. American Journal of Health System Pharmacy. 2008 December 1;65:2273-5.

[39]. Vasileff H, Whitten L, Pink J, Goldsworthy S, Angley M. The effect on medication errors of pharmacists charting medication in an emergency department. Pharmacy World and Science. 2009 June;31(3):373-9.

[40]. Millan J, Rudolph J, Salow M. Pharmacologic Intervention in Late Life (PILL) Clinic: a geriatric model of care to optimize medication managment. Journal of the American Geriatrics Society. 2007;55(s1):S100.

[41]. Bernstein L, Framptom J, Minkoff N, Stepanian S, Iapicca L, Rollo J, et al. Medication reconciliation: Harvard Pilgrim Health Care's approach to improving outpatient medication safety. Journal of Healthcare Quality. 2007;29(4):40-5. 
[42]. Jones R. The role of health kiosks in 2009: Literature and informant review. International Journal of Environmental Research and Public Health. 2009;6:1818-55.

[43]. Yackey B. Myth-busting - taking aim at seven common misconceptions. Self Service World. 2007(July):17-20.

[44]. Rhoads J, Drazen E. Touchscreen check-in: kiosks speed hospital registration. Oakland: California HealthCare Foundation2009.

[45]. Bourgeois F, Porter S, Valim C, Jackson T, Cook F, Mandl K. The value of patient self-report for disease surveillance. Journal of the American Medical Informatics Association. 2007;14(6):765-71.

[46]. Wolcott N. Commentary: Self-service: Just what the doctor ordered. Self Service World. 2009(March 4):1-3.

[47]. Anonymous. Kiosks win patient kudos and speed registration. Healthcare Benchmarks and Quality Improvement. 2005 February;12(2):20-1.

[48]. Anonymous. Sign-in kiosks shorten waiting room lines. ED Management: The monthly update on emergency department management. 2007 December;19(12):137-8.

[49]. Chisholm D, Young R, McAlearney A. Implementation of a touch-screen new patient registration system: A case study. The Journal of Medical Practice Management: MPM. 2005;21(3):159-62.

[50]. Salaffi F, Gasparini S, Grassi W. The use of computer touch-screen technology for the collection of pateint-reported outcome data in rheumatoid arthritis: comparison with standardized paper questionnaires. Clinical and Experimental Rheumatology. 2009;27:459-68.

[51]. Fann J, Berry D, Wolpin S, Austin-Seymour M, Bush N, Halpenny B, et al. Depression screening using the Patient Health Questionnaire-9 administered on a touch screen computer. Psycho-Oncology. 2008;18:14-22.

[52]. Aagaard E, Nadler P, Adler J, Maselli J, Gonzales R. An interactive computer kiosk module for the treatment of recurrent uncomplicated cystitis in women. Journal of General Internal Medicine. 2006;21:1156-9.

[53]. Bischoff-Ferrari H, Vondechend M, Bellamy N, Theiler R. Validation and patient acceptance of a computer touch screen version of the WOMAC 3.1 osteoarthritis index. Annals of Rheumatoid Disease. 2005;64:80-4.

[54]. Porter S, Cai Z, Gribbons W, Goldmann D, Kohane I. The Asthma Kiosk: A patient-centered technology for collaborative decision support in the emergency department. Journal of the American Medical Informatics Association. 2004;11:458-67.

[55]. Dixon S, Bunker T, Chan D. Outcome scores collected by touchscreen: medical audit as it should be in the 21st century? Annals of the Royal College of Surgeons of England. 2007;89:689-91.

[56]. Agha Z, Lofgren R, VanRuiswyk J, Layde P. Are patients at Veterans Affaris medical centers sicker? Archives of Internal Medicine. 2000;160:3252-7.

[57]. US Census Bureau. Oregon Veteran Status: survey statistics. Washington, DC2008 [cited 2010 October 8].

[58]. Society HIaMS. EMR Adoption Model. Chicago: HIMSS Analytics; 2010 [cited 2010 February 1, 2010]; Available from: http://www.himssanalytics.org/hc_providers/emr_adoption.asp.

[59]. DesRoches C, Campbell E, Rao S, Donelan K, Ferris T, Jha A, et al. Electronic health records in ambulatory care: A national survey of physicians. The New England Journal of Medicine. 2008;359:50-60.

[60]. Jylha V, Saranto K. Electronic documnetation in medication reconciliation - a challenge for health care professionals. Applied Nursing Research. 2008;21:237-9.

[61]. Schnipper J, Gandhi T, Wald J, Grant R, Poon E, Volk L, et al. Design and implementation of a webbased patient portal linked to an electronic health record designed to improve medication safety: the Patient Gateway medications module. Informatics in Primary Care. 2008;16:147-55.

[62]. Lesselroth B, Adams S, Yang J, Adams K, Church V, Felder R, et al. The impact of an automated medication reconciliation kiosk on primary care compliance standards. [Poster]. In press 2010. 
[63]. Vergidis K, tiwari A, Majeed B. Business process analysis and optimization: Beyond reengineering. IEEE Transactions on Systems, Man, and Cybernetics - Part C: Applications and Reviews. 2008;38(1):69-82.

[64]. Anthony D, Chetty V, Kartha A, McKenna K, Rizzo DePaoli M, Jack B. Re-engineering the hospital discharge: An example of a multifaceted process evaluation. Advances in Patient Safety. 2005;2:379-94.

[65]. Su Q, Yao X, Su P, Jinghua, Shi, Zhu Y, et al. Hospital registration process reengineering using simulation method. Journal of Healthcare Engineering. 2010;1(1):67-82.

[66]. Kusiak A, Larson N, Wang J. Reengineering of design and manufacturing processes. Computer and Industrial Engineering. 1994;26(3):521-36.

[67]. Perlin J, Kolodner R, Roswell R. The Veterans Health Administration: Quality, value, accountability, and information as transforming stategies for patient-centered care. American Journal of Managed Care. 2004;10(part 2):828-36.

[68]. Lesselroth B, Felder R, Adams S, Cauthers P, Dorr D, Wong G, et al. Design and implementation of a medication reconciliation kiosk: the Automated Patient History Intake Device (APHID). Journal of the American Medical Informatics Association. 2009;16:300-4.

[69]. Imagine That I. ExtendSim. 7 ed. San Jose, CA2002. p. Process simulation software.

[70]. Cayirli T, Veral E. Outpatient scheduling in health care: A review of literature. Production and Operations Management. 2003;12(4):519-49.

[71]. Jun J, Jacobson S, Swisher J. Application of discrete-event simulation in health care clinics: a survey. Journal of the Operational Research Society. 1999 February 9;50:109-23.

[72]. Eitel D, Rudkin S, Malvehy MA, Killeen J, Pines J. Improving service quality by understanding emergency department flow: A white paper and position statement prepared for the American Academy of Emergency Medicine. The Journal of Emergency Medicine. 2010;38(1):70-9.

[73]. Lesselroth B, Adams S, Felder R, Dorr D, Cauthers P, Church V, et al. Using consumer-based kiosk technology to improve and standardize medication reconciliation in a specialty care setting. Joint Commission Journal on Quality and Patient Safety. 2009;35(5):263.

[74]. Walston SL, Lawton RB, Kimberly J. Does reengineering really work? Health Services Research. 2000;34(6):1363-88.

[75]. Nester T, Hale L. Effectiveness of a pharmacist-acquired medication history in promoting patient safety. American Journal of Health System Pharmacy. 2002;59(November):2221-5. 



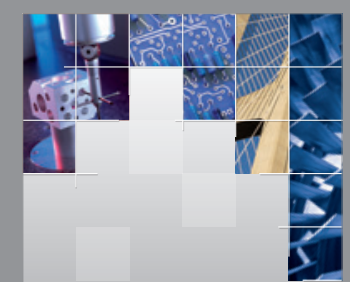

\section{Enfincering}
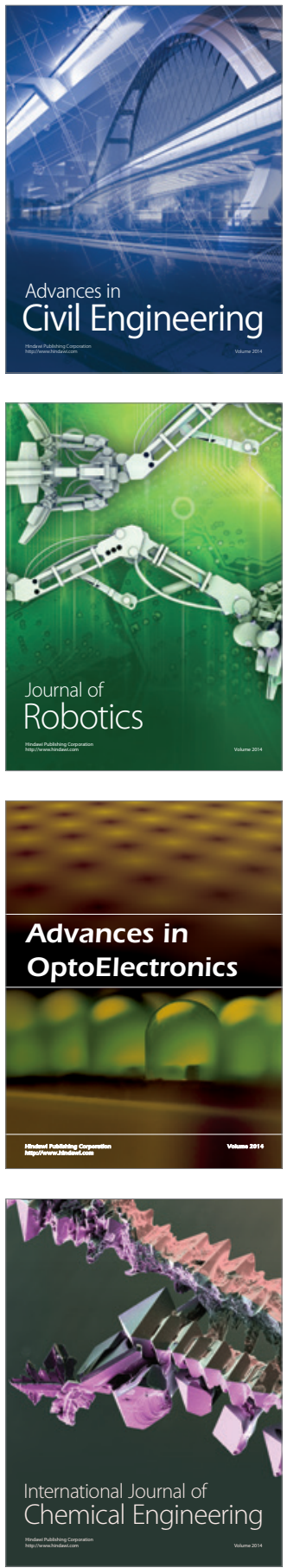

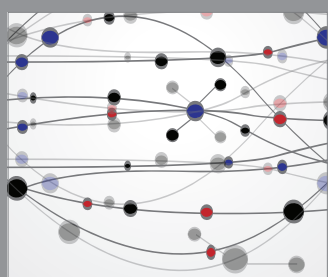

The Scientific World Journal

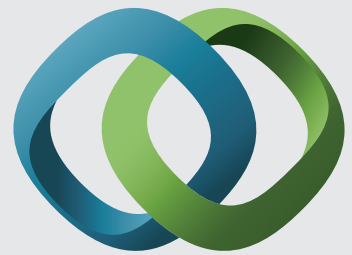

\section{Hindawi}

Submit your manuscripts at

http://www.hindawi.com
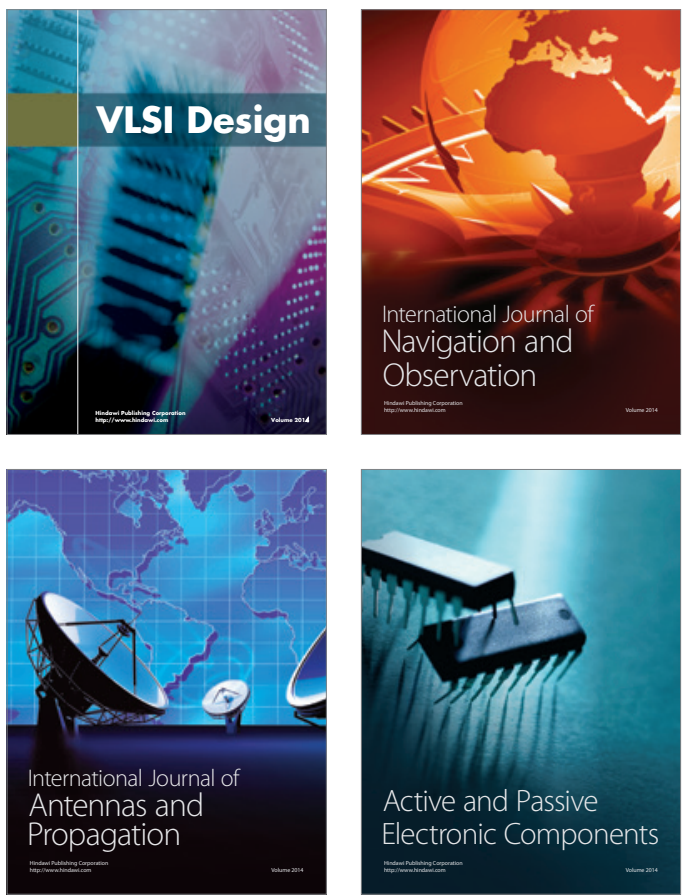
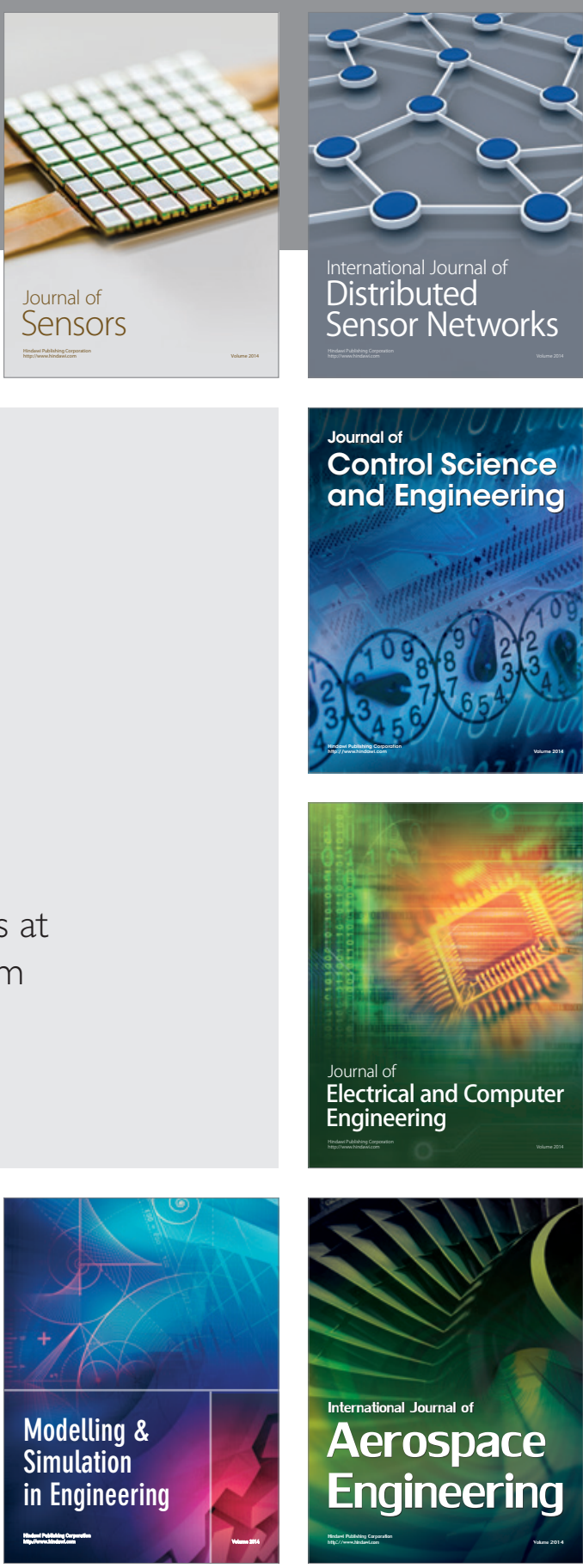

International Journal of

Distributed

Sensor Networks

Journal of

Control Science

and Engineering
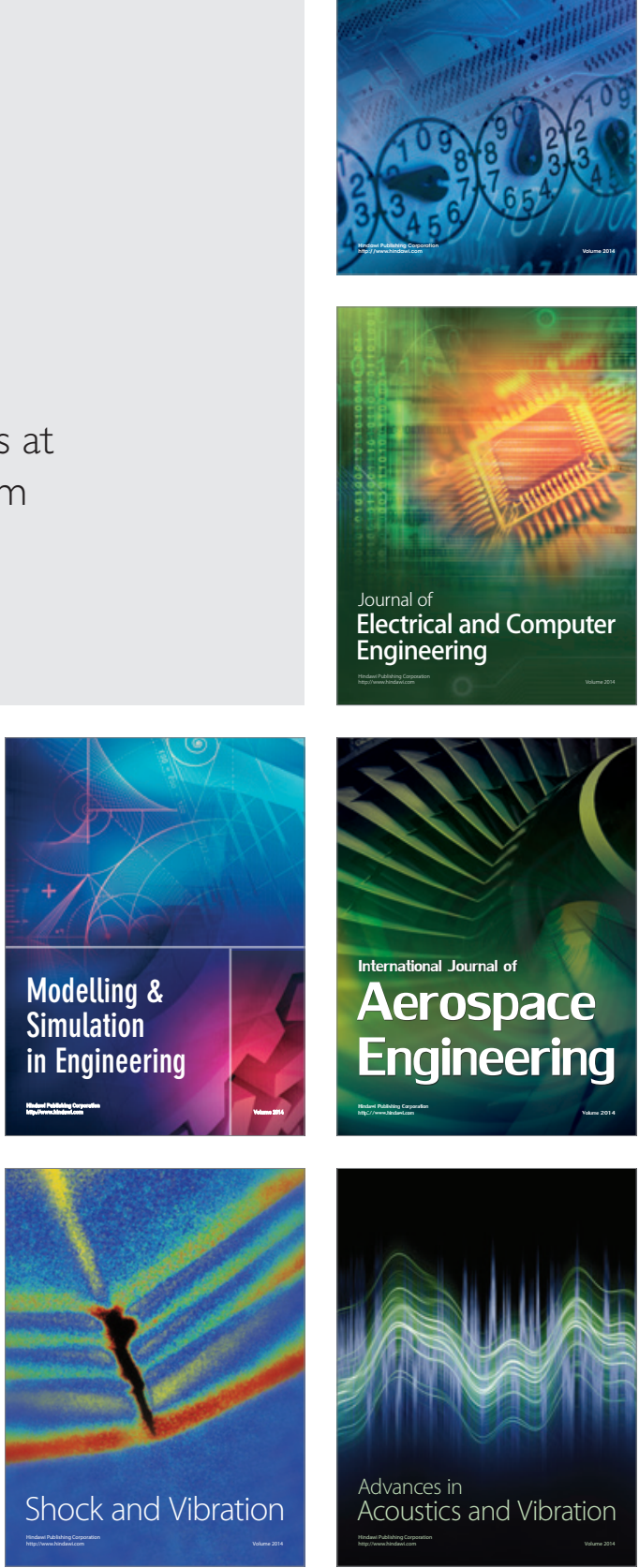